\title{
Granulometric Characterization and Alteration during Composting of Industrial Cork Residue for Use as a Growing Medium
}

\author{
E. Carmona ${ }^{1}$, J. Ordovás ${ }^{2}$, M.T. Moreno ${ }^{2}$, and M. Avilés ${ }^{2}$ \\ Departamento de Ciencias Agroforestales, Universidad de Sevilla, EUITA, \\ Ctra. Utrera, Km. 1, 41013 Seville, Spain
}

\author{
M.T. Aguado ${ }^{3}$ and M.C. Ortega ${ }^{3}$ \\ Escuela Universitaria de Ingenieros técnicos Agrícolas, Cortijo de Cuarto, \\ Apartado 11043, 41014 Seville, Spain
}

\begin{abstract}
This work describes the granulometry of industrial cork residue (bark of Quercus suber L.) and its possible alteration during composting to eliminate the high content of phytotoxic substances. Because of the differences in density of the different-sized cork particles, expression of the granulometric distribution in relation to volume reflected the size distribution more accurately than its expression in relation to weight. As a consequence, predictions of the physical and hydrological behavior of the substrate, deduced from its granulometry, were more accurate when this was calculated in relation to volume. Objective parameters used for textural comparison, such as the geometric mean $\left(d_{g}\right)$ and standard deviation of particle size $\left(\sigma_{\mathrm{g}}\right)$, which were previously used in soils, were tested. These permit the estimation of small differences in the particle size of different lots or the granulometric alteration occurring during composting. With the same purpose, a new diagram of textures for the classification of granular substrates was also studied.
\end{abstract}

Several works have demonstrated the value of industrial cork residue (ICR) (the bark of Quercus suber) as a growing medium (Aguado et al., 1993a, 1993b; Moreno, 1994; Moreno et al., 1995). Because of high phenolic content, it must be composted for 2.5 to 4 months. Appropriate management of the composting process is required to reduce the concentration of these phytotoxins to levels not toxic for plants and to simultaneously avoid significant immobilization of nitrogen (Carmona, 1999; Carmona et al., 1999).

The particle size of the medium affects the size and distribution of the pores and air and water relationships. Therefore, the particle size affects irrigation scheduling and plant growth (Kenneth et al., 1987). For this reason, granulometric analysis is considered a routine practice for substrate characterization (Pokorny and Henny, 1984). Also, by analogy with the procedure used for natural soils, some authors have tried to relate the granulometry of new materials with their hydrological properties (Burés et al., 1997; Richards et al., 1986).

Description of the granulometry of a substrate based on the percent weight of each size fraction could lead to errors, since the particle

Received for publication 25 Feb. 2002. Accepted for publication 31 Dec. 2002. This work was financed by the CICYT as part of the AGF94-0941 Project.

${ }^{1}$ Professor. Departamento de Ciencias Agroforestales, Universidad de Sevilla. To whom reprint requests should be addressed: e-mail address: eusebio@us.es

${ }^{2}$ Professor. Departamento de Ciencias Agroforestales, Universidad de Sevilla.

${ }^{3}$ Professor. Escuela Universitaria de Ingenieros Técnicos Agrícolas. Cortijo de Cuarto. Sevilla. density is not the same in all fractions or, if there are differences in the internal porosity, the proportion in weight does not reflect the proportion in volume of the different sized particles. In the case of cork, in which the non-occluded internal porosity is similar in different fractions, relative volume can be obtained by dividing the proportion in weight by the pseudoreal density (Carmona, 1999; Ordovás et al., 1996).

The classical texture triangle does not conserve the information relating to the particle size distribution between soil samples. To avoid this limitation, Shirazi and Boersma (1984) proposed that soils be described as a function of two statistical parameters: the geometric mean of the particle diameter $\left(\mathrm{d}_{\mathrm{g}}\right)$ and the standard deviation of the mean $\left(\sigma_{\mathrm{g}}\right)$, which reflects the homogeneity of the sizes in the sample. Amixture of particles perfectly homogeneous in size, e.g., isodiametric spheres, would have a $\sigma_{\mathrm{g}}$ of 1.0. Shirazi and Boersma (1984) assumed that the size distribution of soil particles approximately fits a normallogarithmic curve. This would imply that $d_{g}$ represents the particle diameter, which corresponds to a probability distribution of $50 \%$, with most of the particles having a diameter of between $\mathrm{d}_{\mathrm{g}} \times \sigma_{\mathrm{g}}$ and $\mathrm{d}_{\mathrm{g}} / \sigma_{\mathrm{g}}$.

In some works on substrates, these statistical parameters are used to describe the granulometry of media and to detect alterations due to the use of organic and peat-based materials (Michiels et al., 1993) or minerals such as perlites (Orozco and Marfà, 1995). Likewise, the $\mathrm{d}_{\mathrm{g}}$ of different mineral substrates (sands and expanded and non-expanded perlites) has been used to model some physical properties such as porosity, water-air relationships, or hydraulic conductivity (Burés et al., 1997).

Shirazi and Boersma (1984) also proposed a new diagram for the textural classification of soils that integrates the granulometric description by statistical geometric parameters and separation into textural classes by the classical textural triangle. One advantage of this unified diagram is that differences can be established between soils of the same textural class, both in mean particle size and in the homogeneity of its granulometry.

At present, the number of different sieve sizes used for the analysis determines the number of granulometric classes distinguished in substrates. This greatly complicates development of a textural classification of these materials, like the classical triangle method used in soils. Some authors (Marfà, 1995; Orozco, 1995; Orozco et al., 1997) have suggested that a form of the unified diagram of textures proposed by Shirazi and Boersma (1984) adapted for application to substrates be used, taking into account the granulometric differences between these materials and natural soils.

The aim of this work is the granulometric characterization of cork-based substrates and to study its possible alteration during composting. With the same purpose, the unified diagram of textures for the classification of granular substrates proposed by Orozco et al. (1997) was tested.

\section{Material and Methods}

Samples of ICR from years: 1993 (C-93), 1994 (C-94), and 1996 (C-96) were studied. Cork from C-93 composted for: 4 months (CC-4); 7 months (CC-7); and 10.5 months (CC-10.5) were also studied granulometrically, in an attempt to detect possible changes in particle size during the composting. Also, the lots used by Moreno (1994): M-1, M-2, and M-3 were included in an attempt to determine the variability between lots in the same year.

Granulometric analysis of each lot was carried out according to the procedure proposed by Martínez (1992). Samples of 20 to $100 \mathrm{~g}$ were air-dried for 1 month and separated by using the following sieve sizes: 2, 1, 0.5, 0.25, and $0.125 \mathrm{~mm}$. They were then separated by an electromagnetic sieve shaker at maximum vibrations for 10 to $20 \mathrm{~min}$. The operation was repeated 10-12 times for each lot. The percent weight of each fraction was expressed as the arithmetic mean of the different repeat measurements.

From the percentage in weight of each fraction and the pseudoreal density (Gras, 1987), or the density of particles including the volume of occluded pores, the distribution in relation to weight was transformed into the distribution in relation to volume. For this purpose, the pseudoreal density values calculated by Ordovás et al. (1996) for different-sized particles of ICR and cork compost were used.

The granulometric distribution of the particles studied by Moreno (1994) was determined using a different set of sieve sizes of: 3 , $2,1,0.5$, and $0.2 \mathrm{~mm}$, which did not facilitate comparison of data. The transformation of these data into a granulometric distribution 
in relation to volume was done by assuming that similar-sized fractions had the same pseudoreal density. Two statistical parameters were calculated with the data obtained: the geometric mean of particle diameter $\left(\mathrm{d}_{\mathrm{g}}\right)$ and the standard deviation of the mean $\left(\sigma_{\mathrm{g}}\right)$, as follows:

$$
\begin{aligned}
& d_{g}=\exp (a) ; \quad \sigma_{g}=\exp (b) \\
& \left.a=\sum_{i=1}^{n} m i \cdot \operatorname{In} d i ; \quad b=\sum_{i=1}^{n} m i(\operatorname{In} d i)^{2}-a^{2}\right]^{1 / 2}
\end{aligned}
$$

where:

$d i=$ arithmetic mean of two consecutive limits of particle size;

$m i=\mathrm{a}$ unitary fraction of the mass of particles with a diameter within the cited range.

These parameters were used to compare the fit of the granulometric distribution of cork to lognormal distributions, to detect the granulometric variations between the different lots and to try to detect slight changes in granulometry occurring as a consequence of the composting process.

The particles were classified into three different granulometric categories as described by Orozco (1995): a) fine particles, between 0 and $0.5 \mathrm{~mm}$; b) intermediate particles, between 0.5 and $2 \mathrm{~mm}$; and c) large particles, between 2 and $8 \mathrm{~mm}$. Orozco (1995), by analogy with the diagram proposed by Shirazi and Boersma (1984) for soils, developed a table with 66 possible combinations of percentages (at 10\% intervals) of the three fractions described above, such that the sum of the three always amounted to $100 \%$.

The data of $d_{g}$ and $\sigma_{g}$ obtained for each combination were represented on coordinate axes, on which $d_{g}$ appeared on the abscissa and $\sigma_{\mathrm{g}}$ on the ordinate axis.

\section{Results and Discussion}

The cork particles had a polyhedral appearance similar to sand particles. Larger particles were less dense since they have a larger percentage of occluded internal porosity. This was due to the fact that they are mainly composed of pieces of suberose tissue. The finer fractions, called "dust" in the industrial sector, were darker and denser. These finer particles were mainly comprised of so-called impurities of cork (Ordovás et al., 1996): schlerenchyma cells with very thick lignified walls, cells with abundant cellular content rich in tannins and resinous substances, other non-suberose cells, such as inclusions of tissues of the phloem and phelloderm, as well as the "raspa" (outer part of the bark, which is made up by the cells from the phelloderm and the cortex that have dried up and died during the process of separating the bark from the tree and that are impregnated with cellular fluids and other substances).

A comparison of granulometric distributions expressed in relation to weight (Table 1) and volume (Table 2) showed that granulometry of the cork residue from different lots was coarser than that reflected by the expression of this parameter to weight. In materials without internal porosity, such as sand or non-expanded perlite, the proportion of the different fractions differs only slightly when expressed by weight
Table 1. Granulometric distribution (\% by weight) of different lots of industrial cork residue and cork compost. $^{2}$

\begin{tabular}{lcccccr}
\hline & \multicolumn{7}{c}{ Particle size $(\mathrm{mm})$} \\
\cline { 2 - 7 } & $\leq 0.125$ & $>0.125-0.25$ & $>0.25-0.5$ & $>0.5-1.0$ & $>1.0-2.0$ & $>2.0$ \\
\hline C-93 & 9.6 & 12.2 & 20.5 & 24.3 & 24.2 & 9.2 \\
C-94 & 10.1 & 7.1 & 13.6 & 20.6 & 29.9 & 18.7 \\
C-96 & 3.2 & 5.4 & 13.9 & 18.5 & 32.4 & 26.6 \\
CC-4 & 6.2 & 12.8 & 21.9 & 22.8 & 26.4 & 9.9 \\
CC-7 & 4.2 & 10.9 & 21.1 & 27.9 & 28.3 & 7.6 \\
CC-10.5 & 7.2 & 13.9 & 20.1 & 23.9 & 27.4 & 7.5 \\
\hline
\end{tabular}

${ }^{2}$ Industrial cork residue from the lots of 1993 (C-93), 1994 (C-94) and 1996 (C-96), and cork from lot 1993 composted for 4 months (CC-4), 7 months (CC-7), and 10.5 months (CC-10.5).

Table 2. Granulometric distribution (\% by volume) of different lots of industrial cork residue and cork compost. ${ }^{2}$

\begin{tabular}{lcccccc}
\hline & \multicolumn{7}{c}{ Particle size $(\mathrm{mm})$} \\
\cline { 2 - 7 } & $\leq 0.125$ & $>0.125-0.25$ & $>0.25-0.5$ & $>0.5-1.0$ & $>1.0-2.0$ & $>2.0$ \\
\hline C-93 & 6.6 & 8.9 & 16.3 & 21.1 & 29.1 & 18.0 \\
C-94 & 6.5 & 5.2 & 8.2 & 15.1 & 32.9 & 32.1 \\
C-96 & 1.9 & 3.6 & 7.6 & 12.5 & 32.7 & 41.7 \\
CC-4 & 4.4 & 9.5 & 17.6 & 20.2 & 30.4 & 17.9 \\
CC-7 & 3.1 & 8.7 & 17.7 & 25.3 & 30.4 & 14.8 \\
CC-10.5 & 6.1 & 11.6 & 18.0 & 22.5 & 29.1 & 12.7 \\
M-17.8 & 12.0 & 13.7 & 19.2 & 34.7 & 12.6 & \\
M-20.8 & 1.3 & 1.2 & 7.7 & 44.3 & 44.7 & \\
M-33.2 & 5.1 & 19.6 & 21.8 & 34.2 & 16.1 & \\
\hline
\end{tabular}

${ }^{2}$ Industrial cork residue from the lots of: 1993 (C-93), 1994 (C-94) and 1996 (C-96). Cork from lot 1993 composted for: 4 months (CC-4), 7 months (CC-7), and 10.5 months (CC-10.5). Lots of industrial cork studied by Moreno (1994): M-1, M-2, and M-3.

Table 3. Comparison of the granulometries of an expanded perlite (B10) and that corresponding to the industrial cork residue lot (C94) expressed in relation to weight and volume.

\begin{tabular}{lcccccr}
\hline & \multicolumn{7}{c}{ Particle size $(\mathrm{mm})$} \\
\cline { 2 - 7 } & $\leq 0.125$ & $>0.125-0.25$ & $>0.25-0.5$ & $>0.5-1.0$ & $>1.0-2.0$ & $>2.0$ \\
\hline B10 (\% wt) & 11.6 & 9.0 & 15.7 & 22.2 & 24.2 & 17.3 \\
C94 (\% wt) & 10.1 & 7.1 & 13.6 & 20.6 & 29.9 & 18.7 \\
C94 (\% vol) & 6.5 & 5.2 & 8.2 & 15.1 & 32.9 & 32.1 \\
\hline
\end{tabular}

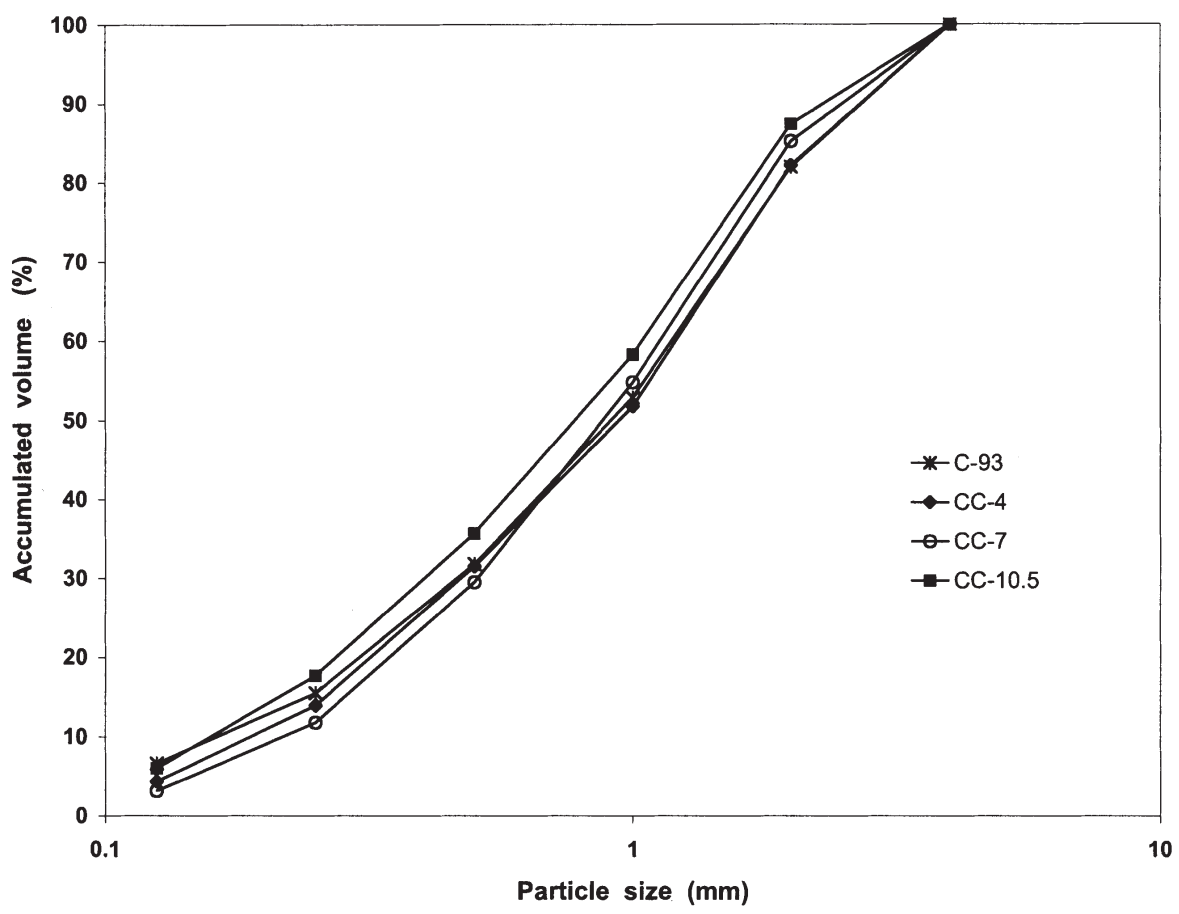

Fig. 1. Cumulative frequency curves of particle size of industrial cork residue (C-93), and composted for 4 (CC-4), 7 (CC-7), and 10.5 (CC-10.5) months. 
Table 4. Values of dg and sg of different lots of cork residue ${ }^{z}$ calculated from their respective granulometric distributions in relation to volume.

\begin{tabular}{lcc}
\hline Lots of cork & $\mathrm{dg}(\mathrm{mm})$ & $\sigma \mathrm{g}$ \\
\hline C-93 & 0.789 & 2.912 \\
C-94 & 1.100 & 2.812 \\
C-96 & 1.437 & 2.378 \\
M-1 & 0.723 & 2.668 \\
M-2 & 1.808 & 1.849 \\
M-3 & 0.892 & 2.492 \\
CC-4 & 0.825 & 2.743 \\
CC-7 & 0.825 & 2.537 \\
CC-10.5 & 0.706 & 2.805 \\
\hline
\end{tabular}

' Industrial cork residue from the lots of: 1993 (C93), 1994 (C-94), and 1996 (C-96). Cork from lot 1993 composted for: 4 months (CC-4), 7 months (CC-7), and 10.5 months (CC-10.5). Lots of industrial cork studied by Moreno (1994): M-1, $\mathrm{M}-2$, and $\mathrm{M}-3$.

and volume. In contrast, ICR is a mixture of particles with different densities. Moreover, the occluded internal porosity could vary in relation to particle size. Therefore, expression of this in relation to volume would give a more accurate description of the granulometric distribution and would better explain the physical and hydrological behavior of this material.

Comparison of the granulometry of C-94 with expanded perlite B10 (Table 3), characterized by Orozco (1995) granulometrically with fractions of a similar pseudoreal density of $0.96 \mathrm{~g} \cdot \mathrm{cm}^{-3}$, showed that the expression of the size distribution as a percentage of weight gave a similar granulometry for both materials. Therefore, if we ignore the fact that one is organic and the other is mineral, we might deduce that both have similar hydrological properties. In contrast, their distribution in relation to volume showed that the granulometry of the cork was in fact considerably coarser.

Samples corresponding to C-93, M-1, and M-3 had similar granulometric distribution (Table 2). C-94, C-96, and M-2 were clearly different.

The variability observed between different lots could be a consequence of different industrial processes (production of bottle corks, sheets, etc.) or the handling and the duration of their storage in piles and possible losses during transport in the loose form. It is, therefore, almost impossible to guarantee a specific granulometry, unless this was controlled by selection or by sieving, which did not usually occur when the material was used for substrate.

Considering the lots studied here, three presented a similar granulometry, with $\approx 31 \%$ of the particles $<0.5 \mathrm{~mm}, 21 \%$ between 0.5 and $1 \mathrm{~mm}$, and more than $48 \%>1 \mathrm{~mm}$. We could consider this distribution in relation to volume as standard in the description of the granulometry of this material.

The similarity between the accumulated curves on a semilogarithmic diagram (Fig. 1) of cork-composted samples and the residue before composting revealed that there was little or no granulometric alteration of this material during composting. The small differences observed were probably only a result of the sampling process. However, it was observed that during the composting process,
Miscellaneous
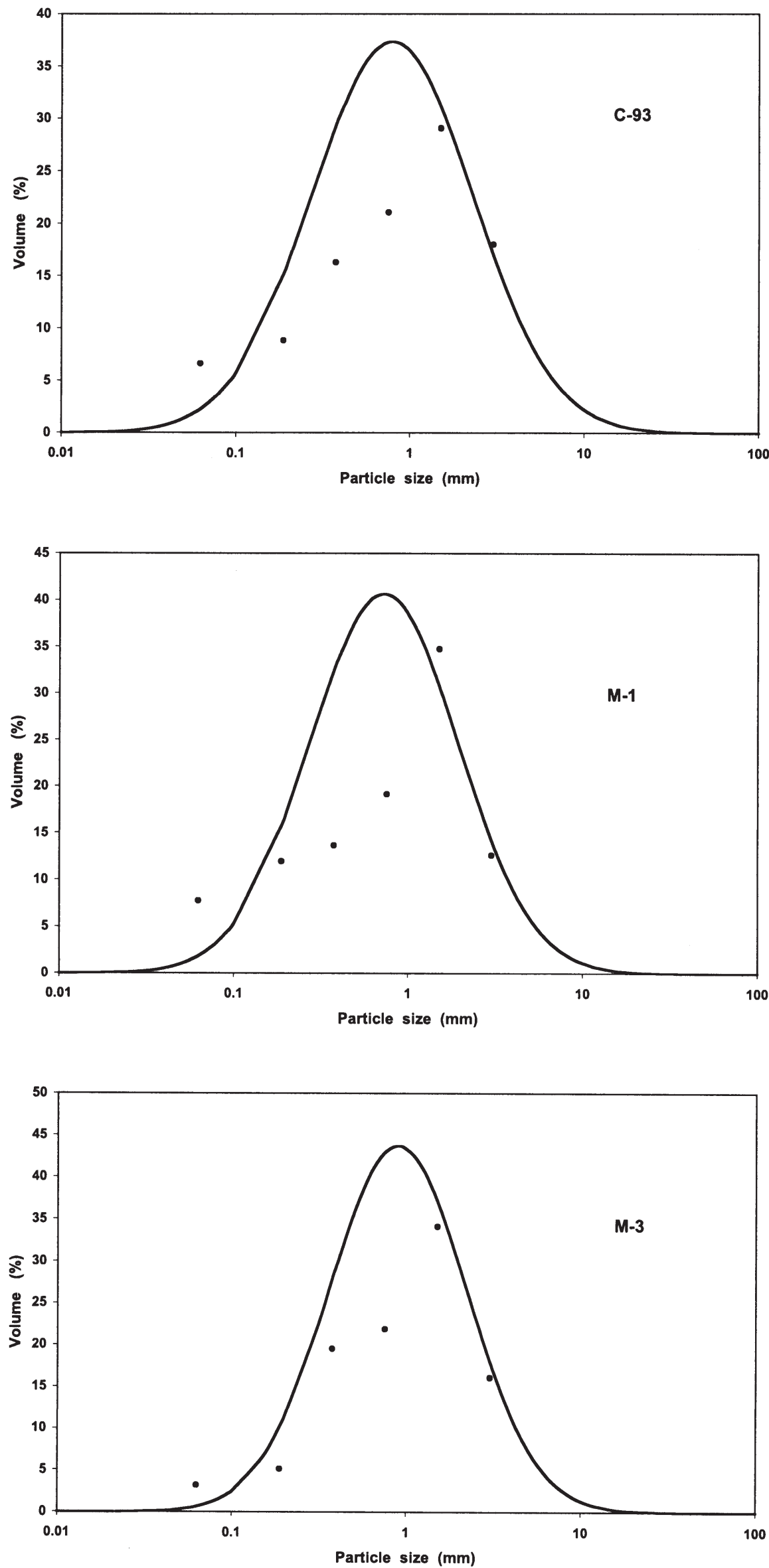

Fig. 2. Adjustment of the granulometric distribution $(\bullet)$ to normal-logarithmic curves. Lots of industrial cork: C-93, M-1, and M-3. Adjustment nonsignificant. 
alterations occured in the porous structure of the particles. These changes included the appearance of new open pores resulting from the perforation of cell walls and a reduction of hydrophobic substances, which significantly affected the hydrological characteristics of the material during its use as a substrate (Carmona, 1999).

Expression of the granulometry using the statistical parameters proposed by Shirazi and Boersma (1984) (Table 4) facilitated the comparison between the substrates. It permitted an objective description using only two parameters: mean size of the particles and the greater or lesser deviation of these from the mean value. Moreover, small differences between the materials could be detected. C93, M-1, and M-3 presented a similar mean particle size (Table 4). C-96 and M-2 were clearly different from the rest in relation to size and the most homogeneous. The very small change in the size and distribution of the granulometry of C-93 during composting was also clearly evident.

The significance levels of the adjustment coefficients to fit a log-normal distribution calculated by the $\chi^{2}$ test were less than $3 \%$. Figure 2 shows this poor fit of the size distribution of the cork residue particles to the Gaussian distribution. In C-93, M-1, and M3 , the distribution was an asymmetric bell shape with a mode of particle size above $d_{g}$. In lots C-94, C-96, and M-2, the distributions (not shown) were not bell-shaped since the mode coincided with the largest-size fraction. Shirazi and Boersma (1984) assumed that the distribution of particle sizes in natural soils fits a normal-logarithmic distribution. However, Shirazi et al. (1988) later suggest that not all soils fit a normal-logarithmic distribution. In certain cases, a bimodal or even a trimodal distribution would better describe the real situation. Buchan (1989) and Shiozawa and Campbell (1991) also questioned the first hypothesis. In a study on six different soils the latter authors found only one that fitted a unimodal normal-logarithmic distribution, and the other five fitted a bimodal distribution better. Orozco (1995), working on perlites, described unimodal distributions although in some cases these poorly fitted a normallogarithmic distribution. Later, Orozco et al. (1997) showed that not all the substrates fitted a Gaussian distribution.

In spite of the fact that the granulometric distribution of the ICR did not fit a normal logarithmic distribution, $d_{g}$ and $\sigma_{g}$ could be used to establish comparisons between substrates.

In an attempt to demonstrate the value of the diagram proposed by Orozco (1995) for substrates, six granulometric fractions of cork lots were grouped and divided into three previously described (Fig. 3). C-93, M1 , and M-3 were found grouped together in the diagram suggesting that they belonged to the same "textural class." In contrast, C-94, C-96, and M-2 were located in clearly different regions, permitting these to be differentiated granulometrically. Similarly, the limited granulometric alteration of C-93 during the

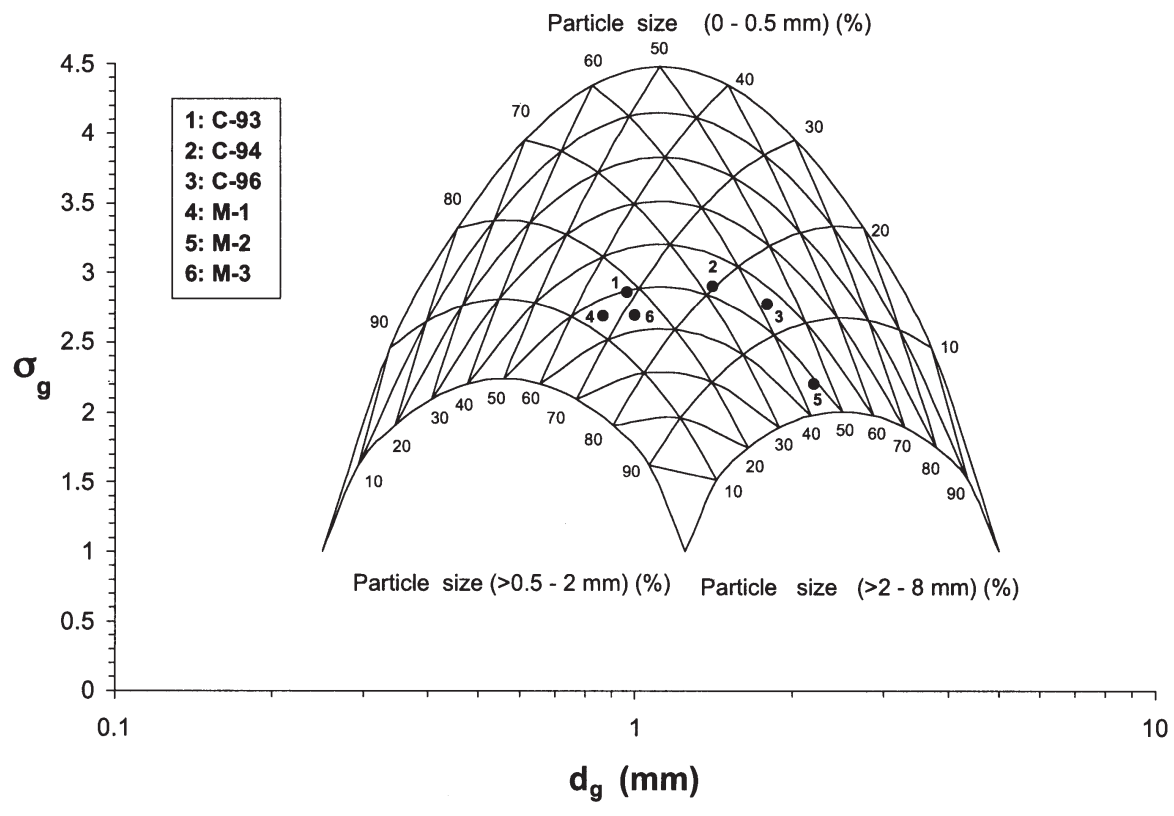

Fig. 3. Location on the diagram of granulometric classification for substrates (Orozco, 1995) of the different lots of industrial cork residue studied. Industrial cork residue from lots of: 1993 (C-93), 1994 (C-94), and 1996 (C-96). Lots of industrial cork studied by Moreno (1994): M-1, M-2, and M-3.

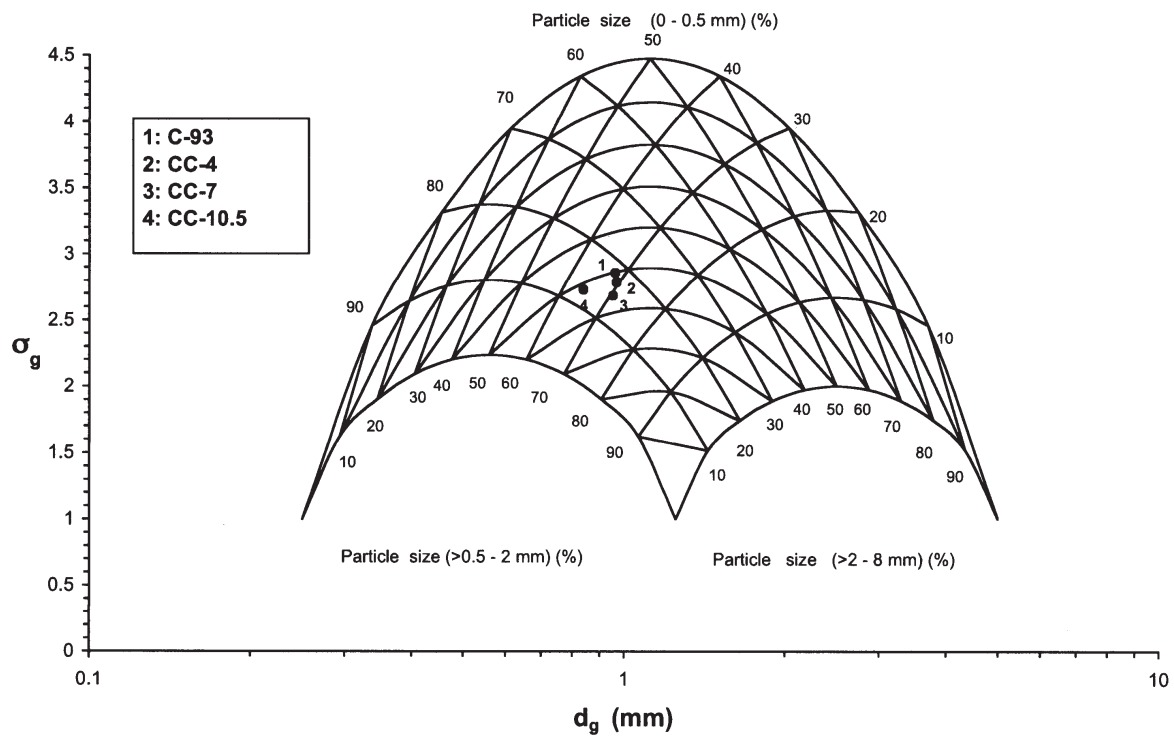

Fig. 4. Location on the diagram of granulometric classification for substrates (Orozco, 1995) of industrial cork residue from lot 1993 (C-93) and composted for 4 (CC-4), 7 (CC-7), and 10.5 (CC-10.5) months.

composting process was confirmed (Fig. 4).

This diagram could be valuable in establishing differences between substrates using only proportions of the three basic particle sizes. Moreover, by facilitating the comparison of distinct lots of substrate separated by different sieve sizes, it could unify different systems of granulometric analysis.

In order to use this methodology to characterize substrates, "textural classes" similar to those used for soils must be developed. Other physical and hydrological properties could be inferred from materials used as growing media. However, the clear differences between mineral and organic substrates in relation to hydrophobic/hydrophilic property, contraction with drying, occluded porosity, formation of aggregates, and biological degradation make it difficult to deduce common physical characteristics by texture alone.

In materials with internal occluded porosity, the granulometric description in relation to volume more accurately reflect the size distribution of the particles than its expression in relation to weight. Therefore, predictions on the behavior of a substrate in relation to its aeration capacity, water retention, hydraulic conductivity, etc., would be more accurate if they were calculated from their granulometric description in relation to volume. This best description of particle size distribution would allow a more appropriate irrigation schedule.

ICR is composed of polyhedral particles 
similar to coarse sand, with an internal porosity and large granulometric variability between lots. Its granulometry in relation to volume had $31 \%$ of its particles $<0.5 \mathrm{~mm} ; 21 \%$ between 0.5 and $1 \mathrm{~mm}$; and $48 \%>1 \mathrm{~mm}$. This distribution had a geometric mean particle size $\left(\mathrm{d}_{\mathrm{g}}\right)$ of $0.789 \mathrm{~mm}$ and a geometric standard deviation of the mean $\left(\sigma_{\mathrm{g}}\right)$ of 2.912 .

Composting of cork residues, at least for durations less than or equal to those studied by us (10.5 months), did not produce a significant alteration in particle size, although it did alter the porous structure and composition.

The use of geometric statistical parameters $\mathrm{d}_{\mathrm{g}}$ and $\sigma_{\mathrm{g}}$ to describe the granulometry and application of these with the textural diagram proposed by Orozco (1995) facilitated the comparison between granular substrates. This was accomplished even when these had been separated by different sieve sizes. The establishment of textural classes in this diagram, from which common physical and hydrological properties could be inferred, could make it a valuable tool in the study of the physical properties of substrates.

\section{Literature Cited}

Aguado, M.T., M.C. Ortega, M.T. Moreno, and J. Ordovás. 1993a. Cultivo de adelfa en sustrato de corcho. Actas Hort. 9:485-488.

Aguado, M.T., M.C. Ortega, M.T. Moreno, and M.P. Suárez. 1993b. Growth and nutrient content of Pelargonium grown in cork oak bark substrate.
Acta Hort. 342:293-296.

Buchan, G.D. 1989. Applicability of the simple log-normal model to particle size distribution in soils. Soil Sci. 147:155-161.

Burés, S., M.C. Gago, O. Morales, O. Marfà, and F.X. Martínez. 1997. Water characterization in granular materials. Acta Hort. 450:389-396.

Carmona, E. 1999. Estudio del compost de corcho como sustrato hortícola y silvícola. PhD Diss., Univ. Politécnica de Valencia.

Carmona, E., J. Ordovás, M.T. Moreno, M.T. Aguado, and M.C. Ortega. 1999. El compost de corcho como sustrato hortícola y silvícola. Agrícola Vergel 18:686-692.

Gras, R. 1987. Propiétés phisiques des substrats, p. 79-126. In: D. Blanc (ed.). Les cultures hors sol. INRA, Paris.

Kenneth, M.T., T.E. Bilderback, and W.C. Fonteno. 1987. Particle size and container size effects on growth of three ornamental species. J. Amer. Soc. Hort. Sci. 112:981-984.

Marfà, O. 1995. La física de sustratos. Algunas perspectivas y desarrollos actuales. Horticultura 103:33-35.

Martínez,F.X. 1992. Propuesta de metodología para la determinación de las propiedades físicas de los sustratos. Actas Hort. 11:55-66.

Michiels, P., R. Hartmann, and C. Coussens. 1993. Physical properties of peat substrates in an ebb/flood irrigation system. Acta Hort. 342: 205-219.

Moreno, M.T. 1994. Estudio del residuo de la industria del corcho como sustrato hortícola. $\mathrm{PhD}$ Diss., Univ. de Sevilla.

Moreno, M.T., M.C. Ortega, J. Ordovás, and M.T. Aguado. 1995. Características químicas del sustrato de corcho. Invest. Agr. Prod. Prot.
Veg. 10:397-406.

Ordovás, J., E. Carmona, M.T. Moreno, and M.C. Ortega. 1996. Characteristics of internal porosity of cork container media. HortScience 31 : 1177-1179.

Orozco, R. 1995. Propiedades físicas e hidrológicas de perlitas utilizadas para cultivos sin suelo. Su implicación con las relaciones sustrato-aguaplanta y con el riego de cultivos hortícolas. PhD Diss., Univ. de Lleida.

Orozco, R. and O. Marfà. 1995. Granulometric alteration, air-entry potential and hydraulic conductivity in perlites used in soilless cultures. Acta Hort. 408:147-161.

Orozco, R., S. Gschwander, and O. Marfà. 1997. Substrate classification from particle size analysis. Acta Hort. 450:397-403.

Pokorny, F.A. and B.K. Henny. 1984. Construction of a milled pine bark and sand potting medium from component particles; II. Medium synthesis. J. Amer. Soc. Hort. Sci. 109:774-776.

Richards, D., M. Lane, and D.V. Beardsell. 1986. The influence of particle-size distribution in pinebark : sand : brown coal potting mixes on water supply, aeration and plant growth. Scientia Hort. 29:1-14

Shiozawa, S. and G.S. Campbell. 1991. On the calculation of mean particle diameter and standard deviation from sand, silt, and clay fractions. Soil Sci. 152:427-431.

Shirazi, M.A. and L. Boersma. 1984. A unifying quantitative analysis of soil texture. Soil Sci. Soc. Amer. J. 48:142-147.

Shirazi, M.A., L. Boersma, and J.W. Hart. 1988. A unifying quantitative analysis of soil texture: improvement of precision and extension of scale. Soil Sci. Soc. Amer. J. 52:181-190. 